\title{
Influence of the Beta Crystalline Phase Fraction on the Mechanical Behavior of Polypropylene/calcium Carbonate/ polypropylene-graft-maleic Anhydride Composites
}

\author{
Rogerio Sakahara \\ Departament of Polymer Science, Braskem S.A., III Pólo Petroquímico, Triunfo, RS, Brazil \\ Aurianny Lima, Shu Hui Wang \\ Departament of Metallurgical and Materials Engineering, Polytechnic School, \\ University of São Paulo - USP
}

\begin{abstract}
The formation of the crystalline phase of polypropylene in the presence of four different types of CaCO $\mathrm{CO}_{3}$ was studied. All composites were prepared by melt mixing and extrusion and the concentration of $\mathrm{CaCO}_{3}$ was maintained at $5 \mathrm{wt} \%$. Furthermore, in another series of composites, $5 \mathrm{wt} \%$ of polypropylene-graft-maleic anhydride (PP-g-MA) was added for comparison. The tensile strength, flexural modulus and impact resistance of the composites were determined. The composites were also analyzed by DSC (differential scanning calorimetry) and WAXD (wide angle x-ray diffractometry) in order to understand and quantify the beta crystalline phase. The results indicated that the composite having the smallest $\mathrm{CaCO}_{3}$ size and PP-g-MA presented the best combined mechanical properties, therefore, the highest impact resistance, flexural modulus and tensile strength were observed, which were attributed to the proportionally higher concentration of beta crystalline phase.
\end{abstract}

Keywords: Polypropylene composite, impact resistance, toughening

\section{Introduction}

Particulate filled isotactic polypropylene (iPP) is widely used for automotive interior and exterior applications, for instance the instrument panel, interior parts and bumpers. Its extensive application is supported by its low cost, good chemical resistance, variable mechanical properties and easy processability, among others. Calcium carbonate is among the most common particulate filler added to iPP in order to reduce its cost and improve its rigidity, although reduction of ductility and toughness is usually observed. Tjong et al. ${ }^{[1]}$ analyzed iPP composites having up to $40 \%$ of $\mathrm{CaCO}_{3}$ and concluded that a drop in impact resistance and yield strength with increasing filler content is due to a decrease in the concentration of the tougher polymer matrix, an increase in the amount of the weaker filler/matrix interface, and to the debonding of the filler from the polymer matrix. Premphet \& Horanont ${ }^{[2]}$ demonstrated that up to $10 \%$ in volume of surface treated $\mathrm{CaCO}_{3}$, iPP composites may exhibit higher impact strength, however, concomitantly, a significant reduction in the tensile yield strength. Many researchers ${ }^{[1-7]}$ have studied the toughening of iPP with $\mathrm{CaCO}_{3}$, so the improvement of the impact strength followed by the reduction of yield strength, flexural strength and modulus of the composites are the ordinary outcome. It was also observed, that among different types of calcium carbonate particles, those which were surface treated and submicron sized gave composites with superior combination of mechanical properties ${ }^{[3-7]}$.
It is well known that isotactic polypropylene (iPP) exhibit four different crystalline forms ${ }^{[8,9-17]}$ : alpha (more common), beta, gama and smectic forms. The gama form has been reported to occur in low molar mass iPP ${ }^{[8]}$, while the beta metastable phase has been shown to occur under quenching in the presence of several nucleating agent, exemplified by quinacridone, sodium orthophthalate, isophthalic and terephthalic acids ${ }^{[8]}$ calcium carbonate $^{[6,7,10]}$, wollastonite, calcium salts of pimelic acid ${ }^{[9,11,12]}$ and aryl amide compounds ${ }^{[13,14]}$, among others. The beta crystalline phase formation in PP is favored by factors which tend to reduce nucleation, i.e. slow growth rates, large temperature gradients and high degrees of superheating ${ }^{[8]}$. The technological interest on the beta phase, fraction and spherulites' size and morphology, relies on its strong influence on the mechanical properties of iPP, including higher impact resistance ${ }^{[1,18-21,22]}$.

In this study, composites based on iPP having calcium carbonate $\left(\mathrm{CaCO}_{3}\right)$ were prepared and their mechanical properties were evaluated. A series of four different types of $\mathrm{CaCO}_{3}$ at $5 \mathrm{wt} \%$, which sizes ranged from $0.9 \mu \mathrm{m}$ to $3.0 \mu \mathrm{m}$, were added to polypropylene and then, the formation of the beta crystalline form was monitored. Concomitantly, a second series was analyzed, in which besides $\mathrm{CaCO}_{3}$, the influence of the presence of polypropylene-graft-maleic anhydride (PP-g-MA) on the crystallization of iPP and its mechanical performance were analyzed as well. 


\section{Experimental}

\section{Materials}

Isotactic polypropylene HP 500N (MFI: $11 \mathrm{~g} / 10 \mathrm{~min}$ at $230{ }^{\circ} \mathrm{C}$ and $2.16 \mathrm{~kg}$ ) was supplied by Braskem and polypropylene - graft - maleic anhydride (PP-g-MA), Polibond 3200 , with $1 \%$ maleic anhydride, MFI at $190^{\circ} \mathrm{C}$, $2.16 \mathrm{~kg}$ (ASTM D-1238) of $115 \mathrm{~g} / 10 \mathrm{~min}$ by Chemtura. Four different particulate natural grounded calcium carbonates were supplied by Provençale, mean diameter sizes of $0.9 \mu \mathrm{m}, 0.9 \mu \mathrm{m}$ (surface treated), $2.5 \mu \mathrm{m}$ and $3 \mu \mathrm{m}$.

\section{Preparation of the composites}

The master-batches were prepared by pre-mixing the components of the blend in a high-speed thermokinetic mixer (MH Equipamentos, model MH-600) at mixer rotor speed of 1800 RPM for $5 \mathrm{~min}$. The master-batches were ground and the composites were prepared by melt extrusion through a single screw extruder (Miotto, model EM-03) (diameter $25 \mathrm{~mm}, \mathrm{~L} / \mathrm{D}=25$ and $50 \mathrm{RPM}$ ), with three heating zones set at 130,150 and $180{ }^{\circ} \mathrm{C}$. Table 1 shows the compositions of the composites prepared in this work.

The specimens for tensile, bending and impact tests, according to ISO 3167, were prepared by using a Battenfeld FB 1400/450 injection molding machine, with four heating zones set at $190,200,210,220^{\circ} \mathrm{C}$ and the mold temperature at $60{ }^{\circ} \mathrm{C}$.

\section{Composites characterization}

Tensile tests were performed at $23{ }^{\circ} \mathrm{C}$ using an Instron Universal Testing Machine (model $5566-10 \mathrm{kN}$ ) at 50 $\mathrm{mm} / \mathrm{min}$, according to ISO 527 . The single cantilever three points bending tests were performed using the same equipment at $2 \mathrm{~mm} / \mathrm{min}$ and the flexural modulus was determined according to ISO 178. Izod impact tests, according to ISO 180/4A, were performed by using a Ceast model Resil Impactor 6967, with specimens at $23{ }^{\circ} \mathrm{C}$ and $-40{ }^{\circ} \mathrm{C}$. The results are expressed in energy lost per unit of thickness, $\mathrm{J} / \mathrm{m}$.

In order to analyze the beta crystalline phase the WAXD (wide angle $\mathrm{x}$-ray diffractometry) spectra were performed on the surface of the injected specimens in a conventional horizontal-axis using a PAnalytical X' Pert PRO equipped with a X'Celerator detector, with $\mathrm{Cu} \mathrm{K}_{\alpha}$ radiation, at $45 \mathrm{~mA}$,
$40 \mathrm{kV}$ and a scan rate of $0.02^{\circ} / \mathrm{min}$, between $2 \theta=3^{\circ}$ and $2 \theta=70^{\circ}$.

Finally, thermal analysis were performed using a Netzsch DSC equipment, model F3 Maia. The samples were heated up to $200^{\circ} \mathrm{C}$ at $10^{\circ} \mathrm{C}$ per minute. Samples were collected from the central portion of the cross-sectional area of the injected specimens and the degree of crystallinity observed for each composite was determined taking into account only the iPP fraction.

\section{Results and Discussion}

\section{Mechanical tests}

The tests were performed according to ISO 527, ISO 178, ISO 180/4A, for tensile, bending and impact tests, respectively. The mechanical testing results are shown in Figure 1, each displayed value represents the mean value of at least 10 specimens.

Regarding the tensile strength, isotactic polypropylene (iPP) and the composites 1, 1S, 2 and 3 presented similar results (Figure 1a), $33 \mathrm{MPa}$, however after PP-g-MA addition, all composites have shown improvement independent of the particle size of the calcium carbonate, although higher resistances were observed for those having smaller particle sizes. For flexural modulus, similar results were observed, a modulus around 1.28 GPa was measured for iPP and the carbonate filled composites, however composite $1 \mathrm{~S}$, having $0.9 \mu \mathrm{m}$ surface treated carbonate, was a little stiffer and a flexural modulus of $1.4 \mathrm{GPa}$ was observed. The composites having PP-g-MA, as expected due to interface strengthening, presented enhanced modulus, however the improvements were much more considerable then those observed for the tensile strength, increasing 20 to $35 \%$. Nevertheless, the relative influence of the particle size and surface treatment was so far observed to follow the tendency of the correspondent composites without PP-g-MA.

The impact resistances at $23^{\circ} \mathrm{C}$ of the carbonate filled composites were lower than that of iPP, as expected, $\sim 35 \mathrm{~J} / \mathrm{m}$ and $38.7 \mathrm{~J} / \mathrm{m}$, respectively, although at $-40^{\circ} \mathrm{C}$, the impact reduction was very small, between 0.3 and $0.7 \mathrm{~J} / \mathrm{m}$ (Figures 1c and 1d). The increment in impact resistance in polypropylene composites having tiny carbonates, for instance, micron and nanosized carbonates have been previously described ${ }^{[6,7,10]}$, however the tests were

Table 1. Characteristics of the polypropylene samples.

\begin{tabular}{ccccc}
\hline sample & $\begin{array}{c}\text { Mean diameter of } \\
\mathrm{CaCO}_{3}(\boldsymbol{\mu m})\end{array}$ & $\begin{array}{c}\text { Surface treatment of } \\
\mathbf{C a C O}_{3}\end{array}$ & $\mathbf{C a C O}_{3}(\%)$ & $(\mathbf{P P}-\mathrm{g}-\mathrm{MA})(\%)$ \\
\hline iPP & - & - & - & - \\
$1 \mathrm{~S}$ & 0.9 & yes & 5 & - \\
1 & 0.9 & no & 5 & - \\
2 & 2.5 & no & 5 & - \\
3 & 3.0 & no & 5 & - \\
$1 \mathrm{SM}$ & 0.9 & yes & 5 & 5 \\
$1 \mathrm{M}$ & 0.9 & no & 5 & 5 \\
2M & 2.5 & no & 5 & 5 \\
3M & 3.0 & no & 5 & 5 \\
\hline
\end{tabular}




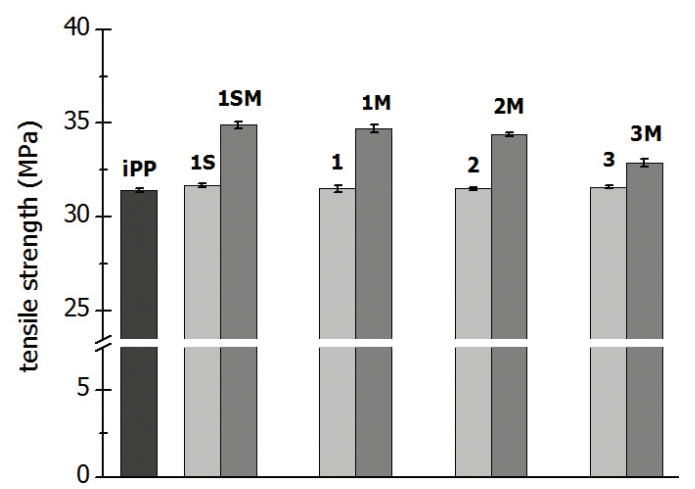

(a)

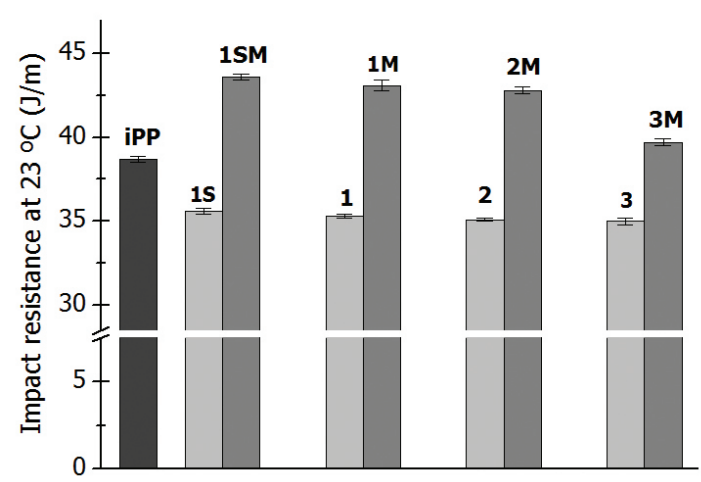

(c)

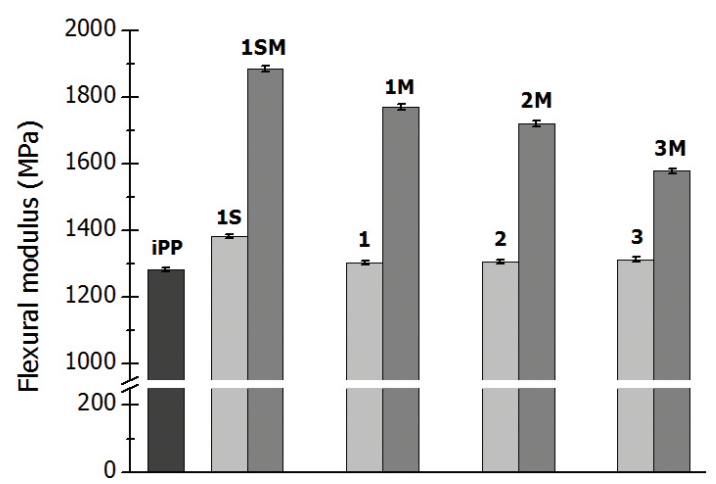

(b)

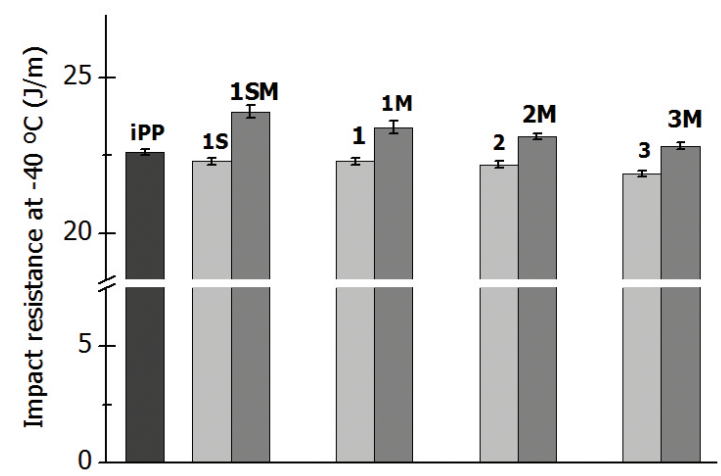

(d)

Figure 1. Summary of the mechanical tests for the composites and iPP.

performed at temperatures equal or higher than $20^{\circ} \mathrm{C}$. Regular $\mathrm{CaCO}_{3}$ particles dispersion is believed to be able to induce small and imperfect PP spherulites formation, decrease the spherulite growth rate and encourage the formation of beta-form PP, and, additionally, allowing matrix-particle debonding by plastic deformation around the particles during impact energy transfer; all together would lead to a significant increase of the notched Izod impact resistance of the composites ${ }^{[6,7]}$.

The use of a lower impact test temperature was important to confirm the increased toughness settled by finer particle and strengthened matrix-filler interface, demonstrated by the results observed for the composites 1S and 1SM, both prepared from surface treated carbonate. Moreover, it is possible to note (Figure 1) that the presence of PP-g-MA in the composites has a significant influence on the mechanical properties of these composites by foster the composite cohesiveness and the matrix toughness. PP-g-MA is a thermoplastic polymer having high polar moieties that is known to enhance adhesion to inorganic and organic polar fillers in polypropylene composites ${ }^{[23,24]}$. The influence of the $\mathrm{CaCO}_{3}$ particles sizes is clearly shown, and finer particles caused larger percentage increase, and additional increment was observed for the composite having the surface treated $\mathrm{CaCO}_{3}$.

The impact resistance at $-40{ }^{\circ} \mathrm{C}$ of iPP did not decrease significantly by the addition of $\mathrm{CaCO}_{3}$, however, when the PP-g-MA was added to the composites considerable increases in resistance were observed, particularly in the presence of finer $\mathrm{CaCO}_{3}$.

\section{WAXD (Wide Angle X-Ray Diffractometry)}

The increase in the mechanical strength of a sample is normally associated to a decrease in its impact resistance. It is not usual to observe an invariable impact resistance in an iPP composition while the mechanical endurance is introduced, and one possible explanation is given by the formation of a new beta crystalline phase ${ }^{[1,2,22]}$.

The identification and quantification of the iPP crystalline structures in the composites were carried out by using WAXD and tentatively by DSC.

The WAXD peaks at $2 \theta$ equal $14.1^{\circ}, 16.8^{\circ}, 18.5^{\circ}$ and $22^{\circ}$ are ascribed to the alpha phase and correspond to the diffraction planes (110), (040), (130) and (111), respectively, while the signal at $2 \theta=16^{\circ}$, diffraction plane (300), is due to the beta phase (Figure 2). iPP displays a plain alpha phase diffraction curve that does not present any sign of the beta phase (Figure 2a). On the other hand, both series, iPP/ $\mathrm{CaCO}_{3}$ (Figure 2b) and iPP/CaCO$/ \mathrm{PP}-\mathrm{g}-\mathrm{MA}$ (Figure 2c) show diffraction curves featuring the characteristic peak at $2 \theta=16^{\circ}$ (300) owing to beta phase. The relative intensity of this peak $\left(2 \theta=16^{\circ}\right)$ reveals the presence and the relative content of the beta structure. A high intensity diffraction 
peak characteristic of $\mathrm{CaCO}_{3}$ is also observed at $2 \theta=29.4^{\circ}$, which is ascribe to calcite (121) plane.

The quantification of the total crystalline amount is calculated by subtracting the amorphous halo of the curve and collecting the intensity of each peak. The quantification of the beta crystalline was carried out by using a previously reported empirical equation (Equation 1) ${ }^{[1,2]}$ :

$$
\mathrm{K}_{\beta}=\frac{\mathrm{H}_{\beta}(300)}{\mathrm{H}_{\alpha}(110)+\mathrm{H}_{\alpha}(040)+\mathrm{H}_{\alpha}(130)+\mathrm{H}_{\beta}(300)}
$$

Where, $K_{\beta}$ is the relative content of the beta phase or the beta crystalline fraction and varies from 0 for a sample with no beta crystals to 1.0 for a sample with only beta crystals $(0=0 \%$ and $1=100 \%)$. The $\mathrm{H}_{\alpha}(110), \mathrm{H}_{\alpha}(040)$ and $\mathrm{H}_{\alpha}(130)$ are the diffraction peak intensities of (110), (040), (130) crystal planes for alpha phase in the sample, while $\mathrm{H}_{\beta}(300)$, corresponds to (300) for beta phase.

The degree of crystallinity and the beta crystalline fraction of each composite were calculated and compared (Figure 3). The composites presented degree of crystallinity in the range from 37 to $59 \%$, observed for the composites 3 and 1SM, respectively. Excluding iPP, all composites presented beta phase that ranged from $4 \%$ to $19 \%$, according to the type of $\mathrm{CaCO}_{3}$ and the presence of PP-g-MA. Moreover, it was possible to observe that $1 \mathrm{SM}$ and $1 \mathrm{M}$

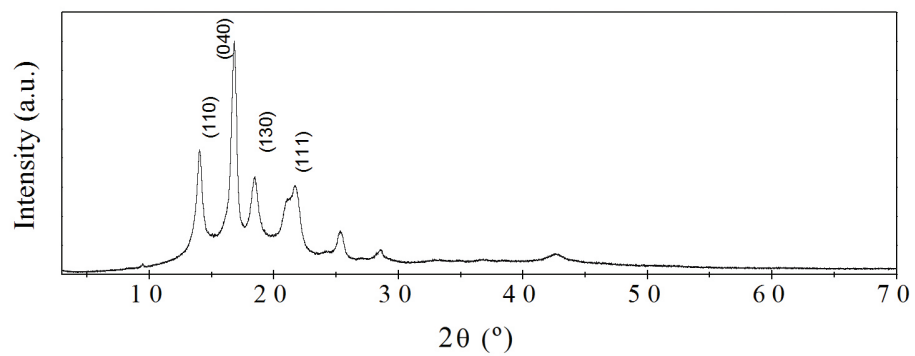

(a)

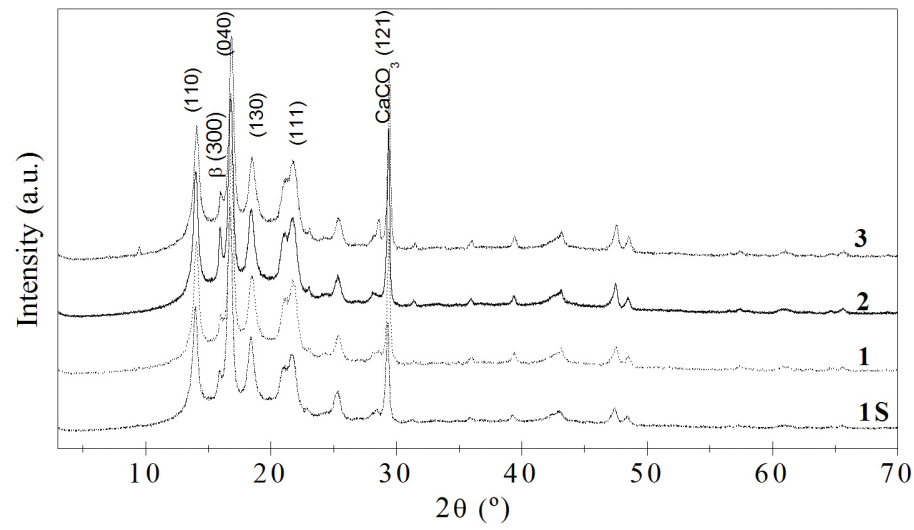

(b)

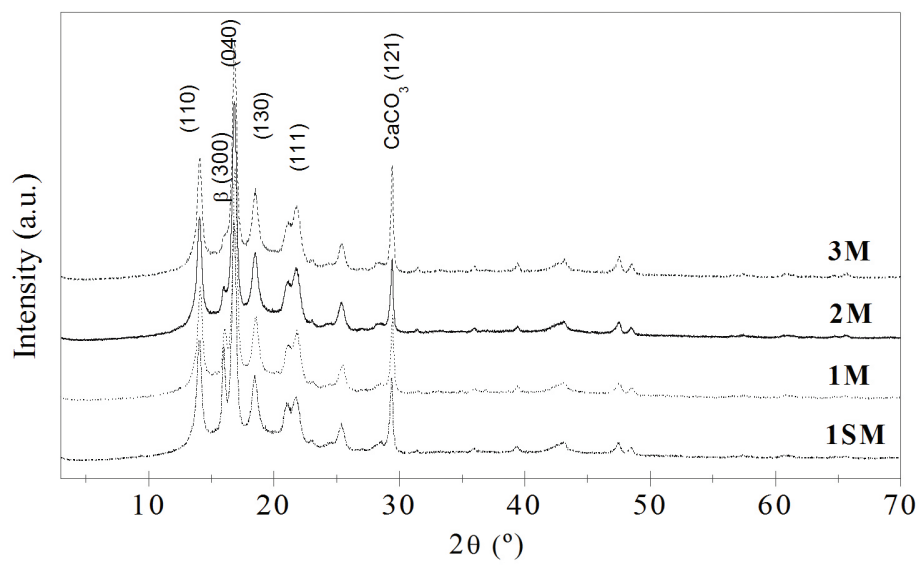

(c)

Figure 2. X-ray diffraction curves for (a) isotactic polypropylene, (b) series $i \mathrm{PP} / \mathrm{CaCO}_{3}$ composites and (c) series $\mathrm{iPP} / \mathrm{CaCO} / \mathrm{PP}-\mathrm{g}-\mathrm{MA}$ composites. 
presented enlarged beta phase formation, demonstrating the synergistic effect of $0.9 \mu \mathrm{m} \mathrm{CaCO}_{3}$ particles, surface treatment and PP-g-MA; thus when PP-g-MA is present, composites having $0.9 \mu \mathrm{m} \mathrm{CaCO}_{3}$ particles presented the highest beta fraction followed by those with $2.5 \mu \mathrm{m}$ and 3.0 $\mu \mathrm{m} \mathrm{CaCO}_{3}$, and $1 \mathrm{SM}$ exhibited even higher beta crystalline

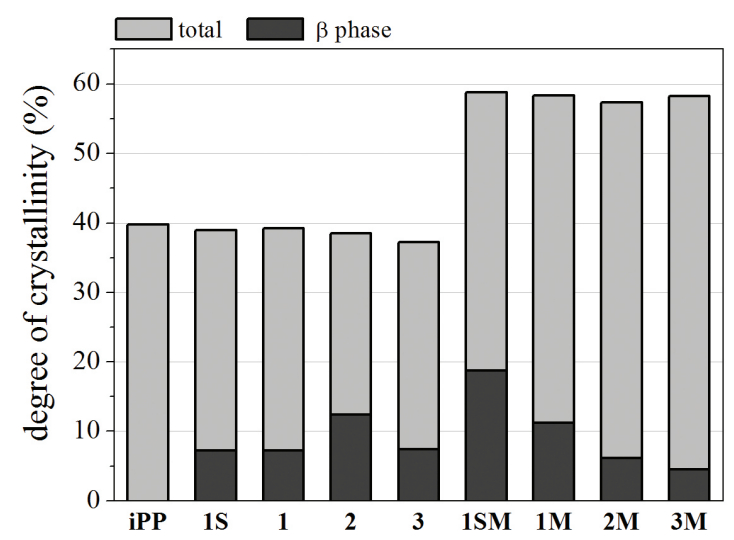

Figure 3. Degree of crystallinity and $\beta$ phase content in iPP and composites.

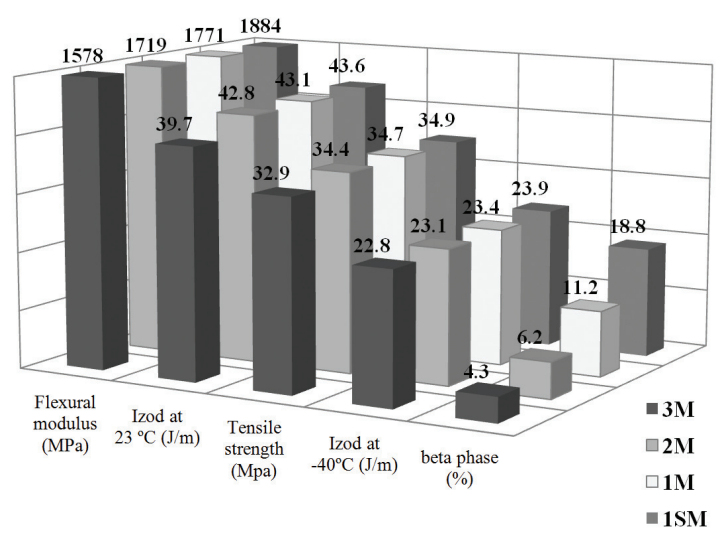

Figure 4. Results of the mechanical tests and the beta crystalline phase fraction for the iPP/CaCO $3 / \mathrm{PP}-\mathrm{g}-\mathrm{MA}$ composites. fraction $\left(\mathrm{K}_{\beta} \sim 19 \%\right)$ compared to $1 \mathrm{M}$, the highest among the samples here prepared. However, Kim et al. analyzed the crystallization of polypropylene in the presence of different PP-g-MA and observed almost exclusively alpha phase structure, which led them to conclude that the development of the hexagonal beta-form crystals would only be privileged through the injection molding temperatures of the process ${ }^{[25]}$. Furthermore, our composites having only $\mathrm{CaCO}_{3}$ did not display any tendency regarding the beta fraction amounts and the particulate sizes, which is not explainable, although its contribution to the beta phase formation is apparent as such crystalline phase was not observed in iPP.

It can be seen in Figure 4 that the increase of the beta crystalline phase fraction is aligned with the strengthening of the mechanical properties here measured. Specifically, for those PP composites having PP-g-MA and $\mathrm{CaCO}_{3}$, the greater the amount of beta crystalline phase the higher the increment observed in impact resistance, flexural modulus and tensile yield strength.

Taken the whole set, it is obvious that the sample produced with the $0.9 \mu \mathrm{m} \mathrm{CaCO}_{3}$ in the presence of PP-g-MA presented the highest amount of beta crystalline phase, which led to a significant improvement on the impact resistance without sacrificing the other mechanical properties. The enhancement of the impact resistance is believed also to partially come from the fact that when a large or rapid deformation event occurs, such as during impact, energy is dissipated through conversion of the metastable beta crystals into alpha crystals while simultaneously developing microvoids ${ }^{[22,27]}$.

\section{DSC (Differential Scanning Calorimetry)}

The DSC analysis is commonly used to assess beta nucleation, and the melting curves are illustrated in Figure 5. As described earlier, small samples having $\sim 10 \mathrm{mg}$ were cut from the molded specimens, sealed in

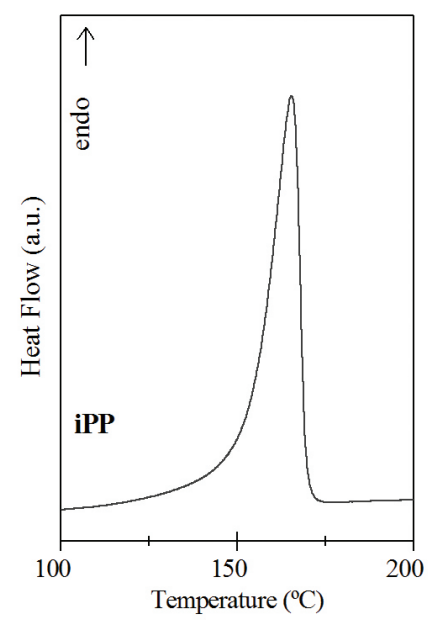

(a)

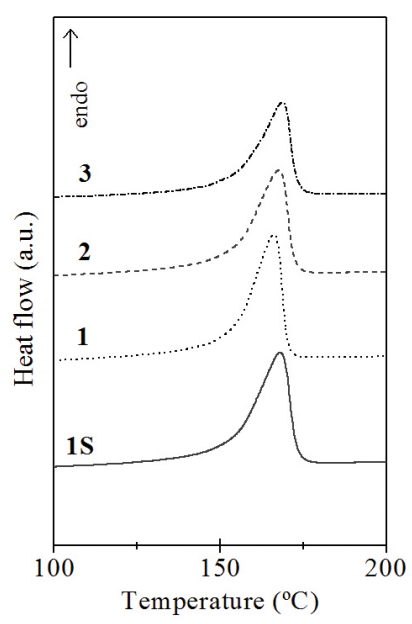

(b)

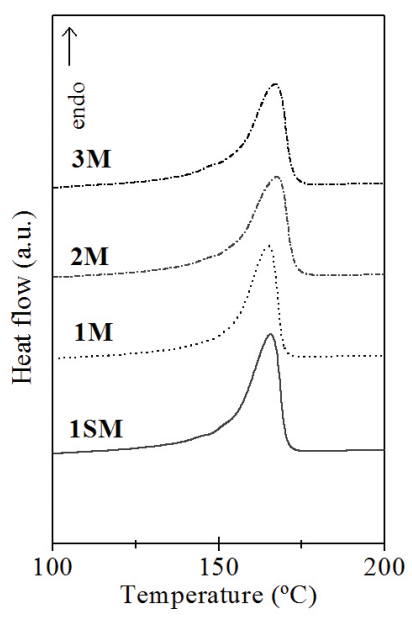

(c)

Figure 5. DSC Heating Curves for (a) iPP, (b) $\mathrm{iPP} / \mathrm{CaCO}_{3}$ series and (c) $\mathrm{iPP} / \mathrm{CaCO}_{3} / \mathrm{PP}-\mathrm{g}-\mathrm{MA}$ series. 
Table 2. Degree of crystallinity determined by DSC.

\begin{tabular}{cc}
\hline Sample & $\mathbf{X}_{\mathbf{c}}(\boldsymbol{\%})$ \\
\hline iPP & 44 \\
$1 \mathrm{~S}$ & 48 \\
1 & 48 \\
2 & 47 \\
3 & 44 \\
$1 \mathrm{SM}$ & 47 \\
$1 \mathrm{M}$ & 45 \\
$2 \mathrm{M}$ & 47 \\
$3 \mathrm{M}$ & 45 \\
\hline
\end{tabular}

aluminum pans and heated up to $200^{\circ} \mathrm{C}$ at $10{ }^{\circ} \mathrm{C} / \mathrm{min}$. The displayed DSC curves correspond to the first heating cycle, as the purpose is to determine the crystalline fractions and compare them to the WAXD results. The composites have shown a broadened melting peak which might be ascribed to two superposed peaks due to alpha and beta crystalline phases. The lower temperature peak (about $150^{\circ} \mathrm{C}$ ) is due to the beta crystalline phase, while that at higher temperature (about $164^{\circ} \mathrm{C}$ ) is due to the melting of the alpha crystalline phase.

The enthalpy associated to each melting peak was calculated in order to quantify the amount of crystalline phase (Equation 2), as the values for the alpha and beta crystalline phases are known as $\Delta \mathrm{H}_{\mathrm{m}(\alpha)}{ }^{\circ}=177 \mathrm{~J} / \mathrm{g}$ e $\Delta \mathrm{H}_{\mathrm{m}(\beta)}{ }^{\mathrm{o}}$ $=168.5 \mathrm{~J} / \mathrm{g}$, respectively ${ }^{[28]}$.

$$
X_{c}=\frac{\Delta H_{m}}{\Delta H_{m}{ }^{\circ}}
$$

The degree of crystallinity of each composite estimated by DSC (Table 2) was considerably different from that obtained from WAXD (Figure 3) analysis, while iPP presented a comparatively smaller discrepancy, 44 and $40 \%$. DSC analyses resulted in higher degrees of crystallinity, which can be explained by the fact that during the heating process, beta crystalline phase melts at comparable lower temperature and can undergo recrystallization to the alpha form, thereby contributing again to the total heat of fusion. As iPP does not present beta crystalline phase, it is possible to observe a smaller difference between WAXD and DSC results.

\section{Conclusions}

Polypropylene (iPP) composites were prepared with four types of $\mathrm{CaCO}_{3}(5 \mathrm{wt} \%)$ and their mechanical properties were analyzed, as well as their microstructure. Differently from iPP, all composites presented beta crystalline phase. It was clearly observed that the beta crystalline phase was more extensively formed in the samples produced with the smallest $\mathrm{CaCO}_{3}$ in the presence of PP-g-MA. It was possible to observe a correlation between the presence of higher beta phase content and the extent of improvement in the mechanical properties (tensile strength, modulus in bending and impact strength), which is explained by the toughness of the beta crystalline phase and its metastability, allowing its conversion to the most common alpha crystalline phase under mechanical load and thermal stress.

\section{References}

1. Tjong, S. C.; Li, R. K. Y. \& Cheung, T. - Polym. Eng. Sci., 37, p.166 (1997). http://dx.doi.org/10.1002/pen.11657

2. Premphet, K. \& Horanont, P. - J. Appl. Polym. Sci., 74, p.3445 (1999). http://dx.doi.org/10.1002/(SICI)10974628(19991227)74:14<3445::AID-APP19>3.0.CO;2-0

3. Chan, C. M.; Wu, J.; Li, J. X. \& Cheung, Y. K. - Polym, 43, p.2981 (2002). http://dx.doi.org/10.1016/S00323861(02)00120-9

4. Zuiderduin, W. C. J.; Westzaan, C.; Huétink, J. \& Gaymans, R. J. - Polym., 44, p.261 (2003). http://dx.doi.org/10.1016/ S0032-3861(02)00769-3

5. Yang, K.; Yang, Q.; Li, G.; Sun, Y. \& Feng, D. - Polym. Comp., 27, p.443 (2006). http://dx.doi.org/10.1002/pc.20211

6. Thio, Y. S. \& Argon, A. S. - Polym., 43, p.3661 (2002). http:// dx.doi.org/10.1016/S0032-3861(02)00193-3

7. Zhang, Q. X.; Yua, Z. Z.; Xiea, X. L. \& Mai, Y. W. Polym., 45, p.5985 (2004). http://dx.doi.org/10.1016/j. polymer.2004.06.044

8. Bruckner, S.; Meille, S. V.; Petraccone, V. \& Pirozzi, B. - Prog. Polym. Sci., 16, p.361 (1991).

9. Moore Jr., E. P. - "Polypropylene handbook", Haser, Ohio, p.113 (1996).

10. Eiras, D. \& Pessan, L. A. - Mat. Res., 12, p.517 (2009). http:// dx.doi.org/10.1590/S1516-14392009000400023

11. Lotz, B. - Polym., 39, p.4561 (1998). http://dx.doi.org/10.1016/ S0032-3861(97)10147-1

12. Trongtosak, K.; Supapol, P. \& Tantayanon, S. - Polym. Test., 23, p.533 (2004).

13. Zhang, P.; Liu, X. \& Li, Y. - Mater. Sci. Eng. A, 434, p.310 (2006). http://dx.doi.org/10.1016/j.msea.2006.07.049

14. Cho, K.; Seheb, D. N.; Choi, J. \& Yang, H. - Polym., 43, p.1407 (2001). http://dx.doi.org/10.1016/S0032-3861(01)00729-7

15. Varga, J.; Mudra, I. \& Ehrenstein, G. W. - J. Appl. Polym. Sci., 74, p.2357 (1999). http://dx.doi.org/10.1002/(SICI)10974628(19991205)74:10<2357::AID-APP3>3.0.CO;2-2

16. Li, J. X. \& Cheung, W. L. - Polym, 40, p.2085 (1998). http:// dx.doi.org/10.1016/S0032-3861(98)00425-X

17. Li, J. X.; Cheung, W. L. \& Jia, D. - Polym., 40, p.1219 (1999). http://dx.doi.org/10.1016/S0032-3861(98)00345-0

18. Zhao, S. \& Xin, Z. - J. Polym. Sci. Polym. Phys., 48, p.653 (2010). http://dx.doi.org/10.1002/polb.21935

19. Li, X.; Wu, H.; Han, L.; Huang, T.; Wang, Y.; Bai, H. \& Zhou, Z. - J. Polym. Sci: Polym. Phys., 48, p.2108 (2010). http:// dx.doi.org/10.1002/polb.22091

20. Xu, L.; Xu, K.; Zhang, X.; Liu, F. \& Chen, M. - Polym. Adv. Technol., 21, p.807 (2010). http://dx.doi.org/10.1002/pat.1506

21. Labour, T.; Vigier, G.; Séguéla, R.; Gauthier, C.; Orange, G. \& Bomal, Y. - J. Polym. Sci: Polym. Phys., 40, p.31 (2002). http://dx.doi.org/10.1002/polb.10068

22. Jacoby, P. - Plast. Add. Comp, 9, p.32 (2007). http://dx.doi. org/10.1016/S1464-391X(07)70068-5

23. Toro, P.; Quijada, R.; Peralta, R. \& Yazdani-Pedram, M. - J. Appl. Polym. Sci., 103, p.2343 (2007). http://dx.doi. org/10.1002/app.24956 
24. Perrin-Sarazin, F.; Ton-That, M. T.; Bureau, M. N. \& Denault, J. - Polym., 46, p.11624 (2005). http://dx.doi. org/10.1016/j.polymer.2005.09.076

25. Kim, H. S.; Lee, B. H.; Choi, S. W.; Kim, S. \& Kim, H. J. Compos Part A Appl Sci Manuf., 38, p.1473 (2007). http:// dx.doi.org/10.1016/j.compositesa.2007.01.004

26. Mathieu, C.; Thierry, A.; Wittmann, J. C. \& Lotz, B. - J. Polym. Sci. Polym. Phys., 40, p.2504 (2002). http://dx.doi. org/10.1002/polb.10309
27. Jacoby, P.; Bersted, B.; Kissel, H. \& Smith, W. - J. Polym. Sci. B Polym Phys, 24, p.461 (1986). http://dx.doi.org/10.1002/ polb.1986.090240301

28. Wang, S. W.; Yang, W.; Xu, Y. J.; Xie, B. H.; Yang, M. B. \& Peng, X. F. - Polym. Test., 27, p.638 (2008). http://dx.doi. org/10.1016/j.polymertesting.2008.04.004

Received: Feb. 18, 2014 Revised: May 14, 2014 Accepted: May 23, 2014 